\title{
An Advanced Transient Concrete Model for the Determination of Restraint in Concrete Structures Subjected to Fire
}

\author{
Ulrich Schneider $^{1}$ and Martin Schneider ${ }^{2}$
}

Received 8 March 2009, accepted 18 September 2009

\begin{abstract}
The advanced transient concrete model (ATCM) is an extended model for concrete in compression at elevated temperature that incorporates elastic, plastic and creep strain as a function of temperature and stress history. The ATCM is applied with the material model of the thermal induced strain model. The non-linear model comprises thermal strain, elastic strain, plastic strain and transient temperature strains and load history modelling of restraint concrete structures subjected to fire. The mechanical strain is calculated as a function of elastic strain, plastic strain and thermal induced strain. The thermal induced strain is relative independent compared to dependence of Young's modulus by load history. Actually the term comprises elastic, plastic and (pure) transient creep strains as we will show. A comparison is given between experimental results with cylindrical specimens and calculated results.

The equations of the ATCM consider a lot of capabilities, especially for considering the irreversible effects of temperature on some material properties. By considering the load history during heating up, an increasing load bearing capacity due to a higher stiffness of concrete may be obtained. With this model it is possible to apply the thermal-physical behaviour of material laws for calculation of structures under extreme temperature conditions.

The effect of load history in highly loaded structures under fire load will be investigated. The theoretical basis is given in this paper.
\end{abstract}

\section{Introduction}

Calculations to predict the deformation rate and load bearing capacity of concrete structures at high temperatures are often based on material models according to the model of the Eurocode 2 model (EC2-Model). In Europe most of the calculations of structures are based on this model. The model is very usable and provides a high level of safety for members under bending and standard fire test conditions. It has not been tested for natural fire conditions that include decreasing temperature conditions (Schneider et al. 1977).

The load bearing capacity of concrete structures can be optimized with models representing a transient material behaviour. Models that are approximated by transient data are more realistic. The following investigation describes the potential when using a new transient concrete model. This model considers thermal induced strain with external load or internal restraint load during heating up. For this model, a realisation of all components of concrete strain is needed. The concrete behaviour is influenced by transient temperature and load history. Various examples of calculation of structural concrete members are given in Schneider et al. (2009a, 2009b) and Li et al. (2009).

${ }^{1}$ Professor, University of Technology Vienna, Karlsplatz Wien, Austria.

E-mail: ulrich.schneider+e206@tuwien.ac.at

${ }^{2}$ Dipl.-Ing., University of Technology Vienna, Karlsplatz, Wien, Austria.
A material model for calculation of siliceous concrete is given in Schneider et al. (2008). This new model is based on a Thermal-Induced-Strain-Model (TIS-Model) and is called advanced transient concrete model (ATCM). Transient conditions during the whole calculation routine are taken into account. The transient load and the real temperature development are considered. Generally an ATCM can be used for every type of concrete; only some parameter must be changed. This examination is based on ordinary concrete with siliceous aggregates.

Both concrete models, EC2-Model and ATCM based on material properties according to TIS-Model (see equation (1)), show a very different behaviour for deformation and restraint stresses during calculation.

\section{Advanced transient concrete model}

\subsection{General definitions}

It is generally agreed that the total strain $\varepsilon_{t o t}$ comprises the following parts:

$$
\varepsilon_{t o t}=\varepsilon_{e l}+\varepsilon_{p l}+\varepsilon_{t r}+\varepsilon_{t h}
$$

where $\varepsilon_{\text {tot }}$ total strain, $\varepsilon_{e l}$ elastic strain, $\varepsilon_{p l}$ plastic strain, $\varepsilon_{t r}$ total transient creep strain and $\varepsilon_{t h}$ thermal dilatation.

It is therefore convenient to write for the pure mechanical strain $\varepsilon_{m}$ :

$$
\varepsilon_{m}=\varepsilon_{e l}+\varepsilon_{p l}+\varepsilon_{t r}=\varepsilon_{t o t}-\varepsilon_{t h}
$$

During an isothermal creep test the following types of 
deformation occur, see Fig. 1.

According to Khoury et al. (1985), in this case the term $\varepsilon_{m}$ is called "load inducted thermal strain." It consists of transient creep (transitional thermal creep and drying creep), basic creep and elastic strains.

Figure 2 shows the evolution of the total strain for specimens under different constant loads during heating up based on the calculation using the concrete model presented in this paper. The high influence of load during transient heating up can be seen. The elastic strain is very small at temperature $\mathrm{T}=20^{\circ} \mathrm{C}$ compared to the high deformation at high temperatures.

In the following the temperature at any time is referred as $\mathrm{T}$ and the maximum experienced temperature as $\mathrm{T}_{\text {max }}$.

\subsection{Thermal strain}

Figure 3 shows the thermal strains of concrete with different aggregates compared with the thermal strain of steel. According to Fig. 3, the line of siliceous concrete with a high siliceous content is calculated according to a regression function.

For $\mathrm{T} \leq 650^{\circ} \mathrm{C}$ is essential:

$$
\begin{aligned}
& \varepsilon_{t h}=6.6 * 10^{-11} * T^{3}-1.7 * 10^{-8} * T^{2} \\
& \quad+9 * 10^{-6} * T+1.369 * 10^{-4}
\end{aligned}
$$

For $\mathrm{T}>650^{\circ} \mathrm{C}$ is essential:

$$
\varepsilon_{t h}=2 * 10^{-8} * T^{2}-3.94 * 10^{-5} * T+0.0342
$$

It is assumed that concrete has generally moisture inside. That is why some thermal effects occur in thermal strain. Drying occurs through capillary pores and micro cracks. Shrinkage is accounted for by the thermal strain as this is usually determined by testing unsealed concrete specimens (Schneider 1982), i.e. shrinkage occurs simultaneously to thermal expansion during transient temperatures.

\subsection{Calculation of mechanical strain \\ 2.3.1 Consideration of load history}

To calculate the mechanical strain, a load factor is introduced. This factor is calculated as follows:

$$
\alpha=\frac{\sigma_{\text {hist }}}{f_{c}\left(20^{\circ} C\right)}
$$

$\sigma_{\text {hist }}$ is the time dependent compression stress due to external loads. In this report the load level $\alpha$ was kept constant during fire exposure. This factor presents the load history and is used for structures that are loaded under compression in the elastic range $\alpha \leq 0.3$ before and during heating. Some researchers adopt higher load levels $\alpha$, e.g. $\alpha \leq 0.6$ as an upper limit for the application of this method.

In compression, thermal induced cracks will be closed. Therefore one can observe a relative increase of stiffness compared to unstressed concrete during first heating. In unstressed concrete members the dehydrata-

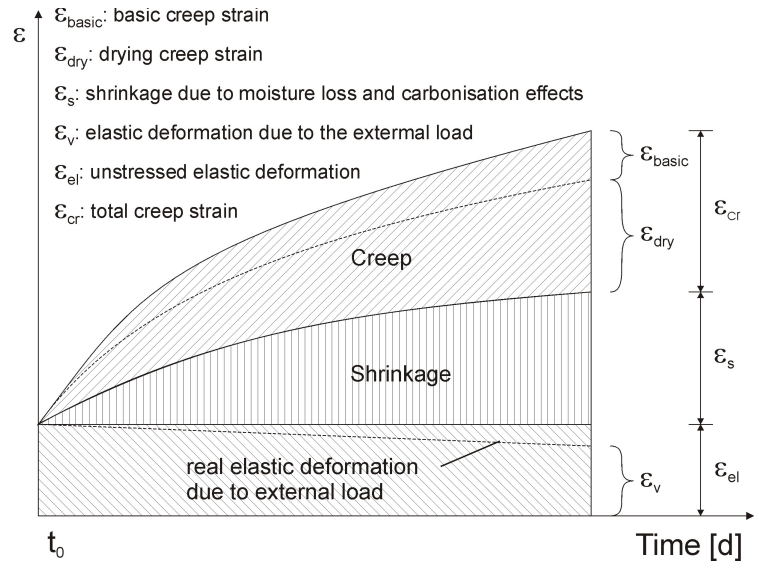

Fig. 1 Deformation of concrete at ambient temperatures subjected to a constant compressive load.

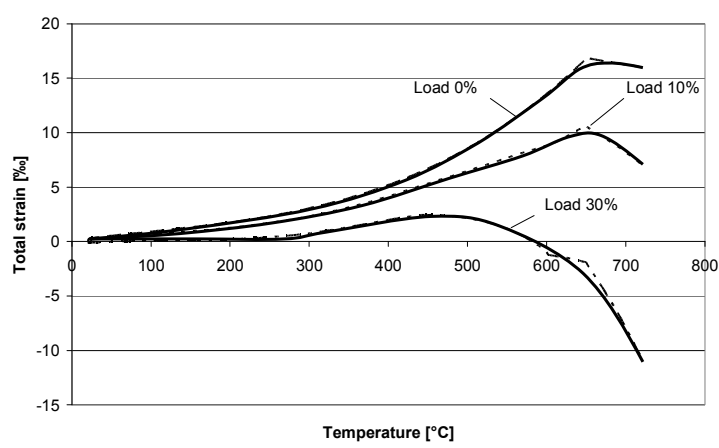

Fig. 2 Total strain at high temperatures as a function of load history.

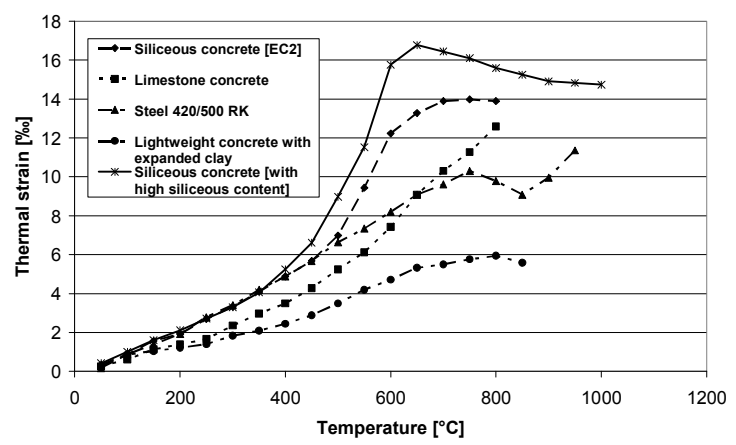

Fig. 3 Thermal strain of concrete with different aggregates and steel. (Schneider et al. 1977, 2008).

tion of cementitious binder generally leads to a decrease in stiffness and compressive strength of concrete (see Fig. 4). Even though this effect also occurs in stressed concrete members the external load and thermal induced stress during heating lead to crack closing.

Figure 4 shows that an increase of the load factor up to $0<\alpha \leq 0.3$ indicates very clearly the relative increase 
of strength compared to $\alpha=0$. A further increase of the load factor does not increase significantly the stiffness.

\subsubsection{Compressive strength}

Figure 5 shows the reduction of compressive strength as a function of temperature for different load histories compared to measurements (Schneider et al. 1977). $f_{c}\left(20^{\circ} \mathrm{C}\right)$ is an experimental result for ordinary concrete tested and cured under RILEM conditions (RILEM TC HTC 200, 2007).

The following equations according to Fig. 5 are based on experimental results. Without load history the behaviour of compressive strength as a function of temperature is according to Schneider (1988).

For $\mathrm{T} \leq 250^{\circ} \mathrm{C}$, the following is essential:

$$
f_{c}(T, \alpha=0)=f_{c}\left(20^{\circ} C\right)
$$

For $250^{\circ} \mathrm{C}<\mathrm{T} \leq 750^{\circ} \mathrm{C}$, the following is essential:

$$
f_{c}(T, \alpha=0)=f_{c}\left(20^{\circ} C\right) *[1-0.0018 *(T-250)]
$$

For $750^{\circ} \mathrm{C}<\mathrm{T} \leq 1000^{\circ} \mathrm{C}$, the following is essential:

$$
f_{c}(T, \alpha=0)=f_{c}\left(20^{\circ} C\right) *[0.1-0.0004 *(T-750)]
$$

For $1000^{\circ} \mathrm{C}<\mathrm{T}$, the following is essential:

$$
f_{c}\left(T, \alpha_{0}\right)=0
$$

With load history the compressive strength is calculated as followed:

For $\mathrm{T} \leq 750^{\circ} \mathrm{C}$, the following is essential:

$$
\begin{aligned}
f_{c}(T, \alpha=0.1) & =f_{c}\left(20^{\circ} C\right) \\
& *\left[-2 * 10^{-6} * T^{2}+4.7 * 10^{-4} * T+0.977\right] \\
f_{c}(T, \alpha=0.3) & =f_{c}\left(20^{\circ} C\right) \\
& *\left[-2 * 10^{-6} * T^{2}+6.8 * 10^{-4} * T+0.9875\right]
\end{aligned}
$$

For $750^{\circ} \mathrm{C}<\mathrm{T} \leq 1000^{\circ} \mathrm{C}$, the following is essential:

$$
\begin{aligned}
& f_{c}(T, \alpha=0.1)=f_{c}\left(20^{\circ} C\right) *[0.25-0.001 *(T-750)] \\
& f_{c}(T, \alpha=0.3)=f_{c}\left(20^{\circ} C\right) *[0.38-0.00152 *(T-750)]
\end{aligned}
$$

For $1000^{\circ} \mathrm{C}<\mathrm{T}$, the following is essential:

$$
\begin{aligned}
& f_{c}(T, \alpha=0.1)=0 \\
& f_{c}(T, \alpha=0.3)=0
\end{aligned}
$$

An interpolation is allowed.

\subsubsection{Young's modulus}

The Young's modulus as a function of load history and temperature, $E(T, \alpha)$ must be measured according to RILEM (RILEM TC HTC 200, 2007) or National Codes with respect to the geometry of specimens being used in the high temperature range, see Fig. 6.

The following equation can be used with $\alpha=0, \alpha=$

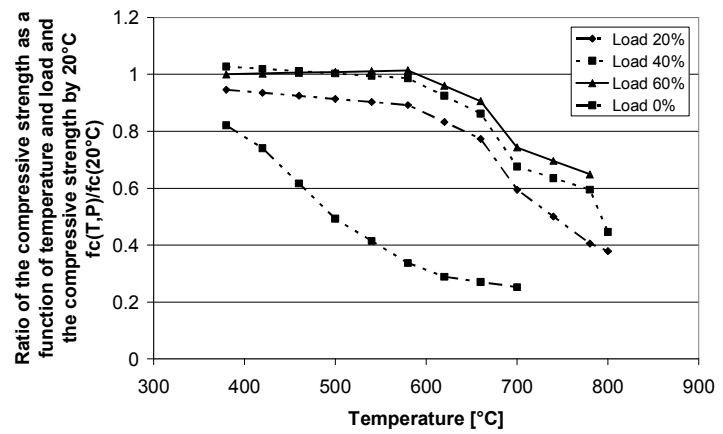

Fig. 4 Comparison of concrete strength for different stress-temperature history. (Shi et al. 2002).

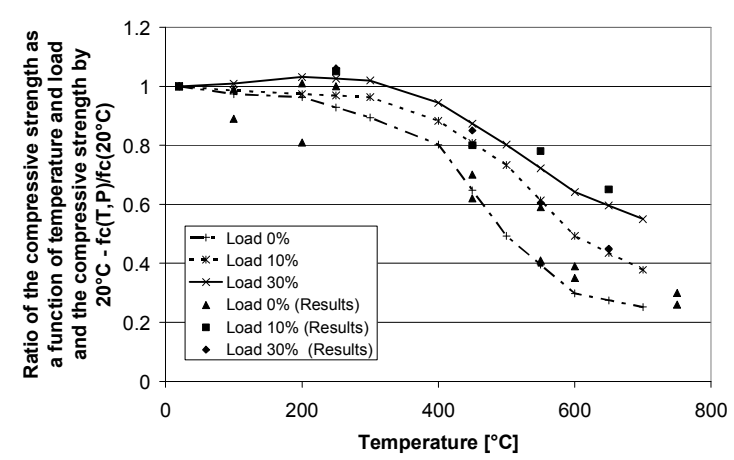

Fig. 5 High temperature compressive strength of siliceous concrete being loaded or not loaded during heating up - experimental and calculated results. (Schneider et al. 1977).

0.1 and $\alpha=0.3$ to calculate Young's modulus at high temperature, based on measurements of $E(T, \alpha)$ according to Fig. 6 (Schneider et al. 1980).

Range I $\left(\mathrm{T} \leq 320^{\circ} \mathrm{C}\right)$ :

$$
\begin{aligned}
E(T, \alpha=0) & =E\left(20^{\circ} C\right) \\
*[100-3 & \left.* 10^{-3} *(T-20)+4.085 * 10^{-6} *(T-20)^{2}\right] \\
E(T, \alpha=0.1) & =E\left(20^{\circ} C\right) \\
* & {\left[3 * 10^{-6} * T^{2}-2.311 * 10^{-3} * T+1.04505\right] } \\
E(T, \alpha=0.3) & =E\left(20^{\circ} C\right) \\
* & {\left[2 * 10^{-6} * T^{2}-1.57 * 10^{-3} * T+1.0306\right] }
\end{aligned}
$$

Range II $\left(320^{\circ} \mathrm{C}<\mathrm{T} \leq 450^{\circ} \mathrm{C}\right)$ :

$$
\begin{aligned}
& E(T, \alpha=0)=E\left(20^{\circ} C\right) \\
& *\left[\begin{array}{l}
0.89406-3.2445 * 10^{-3} \\
* T+1.0081 * 10^{-5}-1.2801 * 10^{-8} * T^{3}
\end{array}\right] \\
& E(T, \alpha=0.1)=E\left(20^{\circ} \mathrm{C}\right) \\
& *\left[-5.1 * 10^{-6} * T^{2}+2.73 * 10^{-3} * T+0.262\right] \\
& E(T, \alpha=0.3)=E\left(20^{\circ} C\right) \\
& *\left[-4 * 10^{-6} * T^{2}+2.5 * 10^{-3} * T+0.342\right]
\end{aligned}
$$




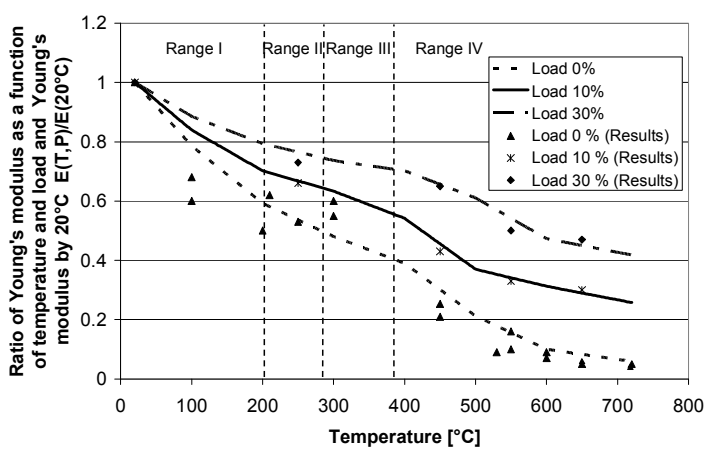

Fig. 6 Influence of high temperature on the Young's modulus of siliceous concrete - experimental and calculated results. (Schneider et al. 1977).

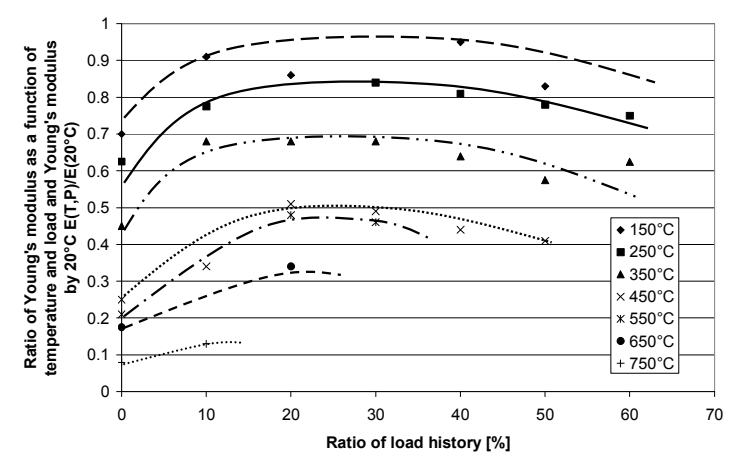

Fig. 7 Young's modulus of siliceous concrete being loaded during heating up. (Schneider 1988).

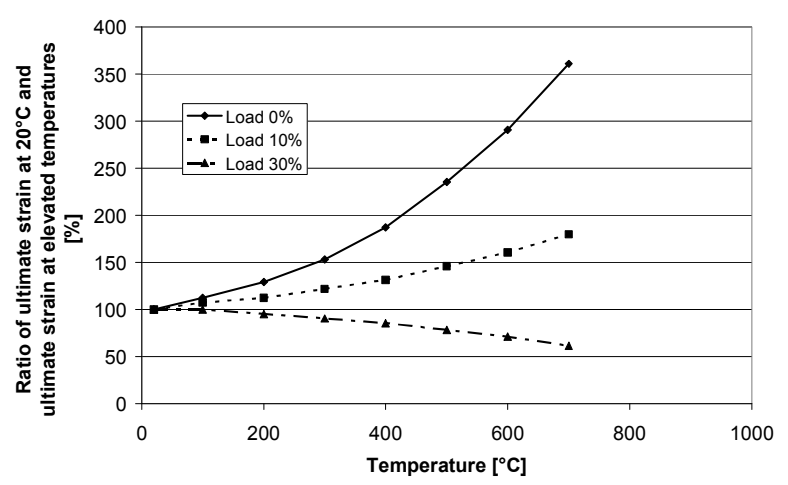

Fig. 8 Ratio of ultimate strain of heated and loaded/nonloaded specimens compared to specimens tested at $20^{\circ} \mathrm{C}$. (Schneider et al. 1977).

$$
\begin{aligned}
& \text { Range III }\left(450^{\circ} \mathrm{C}<\mathrm{T} \leq 600^{\circ} \mathrm{C}\right) \text { : } \\
& E(T, \alpha=0)=E\left(20^{\circ} C\right) *\left[0.45 * e^{-7.52^{*} * 0^{-3} *(T-400)}\right] \\
& E(T, \alpha=0.1)=E\left(20^{\circ} \mathrm{C}\right) \\
& *\left[-6 * 10^{-8} * T^{3}+1 * 10^{-4} * T^{2}-0.056 * T+10.874\right] \\
& E(T, \alpha=0.3)=E\left(20^{\circ} C\right) *\left[1.767 * e^{-0.0022^{*} T}\right]
\end{aligned}
$$

$$
\begin{aligned}
& \text { Range IV }\left(\mathrm{T}>600^{\circ} \mathrm{C}\right) \text { : } \\
& E(T, \alpha=0)=E\left(20^{\circ} \mathrm{C}\right) *\left[e^{-4^{*} 10^{-3} *(T-20)}\right] \\
& E(T, \alpha=0.1)=E\left(20^{\circ} \mathrm{C}\right) *\left[0.82554 * e^{-0.0016^{*} T}\right] \\
& E(T, \alpha=0.3)=E\left(20^{\circ} \mathrm{C}\right) *\left[0.86^{*} e^{-0.001^{*} T}\right]
\end{aligned}
$$

Furthermore it was found that the Young's modulus is relatively constant above $\alpha=0.3$, as shown in Fig. 7 .

Due to the elastic behaviour of stress-strain relationship the Young's modulus in the range before $\alpha=0.3$ increases continuously. After this range, a relatively constant range of the Young's modulus is observed. Then a slightly decrease can be seen. Here the effect of the plastic deformation is noticeable. Considering $\alpha \equiv$ 0.3 is therefore acceptable when $\alpha>0.3$ because the elastic deformation due to the Young's modulus is only in the elastic part of the stress-strain-relationship. The slightly decrease will be considered in the plastic part of the deformation.

The equations are approximated on measured curves that are examined in several experiments with siliceous concrete according to Schneider et al. (1980).

\subsubsection{Ultimate strain}

The ratio between ultimate strain at $20^{\circ} \mathrm{C} \varepsilon_{u}\left(T=20^{\circ} \mathrm{C}\right)$ and ultimate strain as a function of load history and temperature $\varepsilon_{u}(T, \alpha)$ is shown in Fig. 8. It is also based on measurements obtained in the literature (Schneider et al. 1977).

According to Fig. 8, the material behaviour is a function of $f(\alpha), \Delta \varepsilon_{u}(T)$ and $\varepsilon_{u}\left(T=20^{\circ} C\right.$ ) (Schneider 1988). $\varepsilon_{u}(T, \alpha)$ is calculated as follows:

$$
\varepsilon_{u}(T, \alpha)=\varepsilon_{u}\left(20^{\circ} C\right)+\Delta \varepsilon_{u}(T) * f(\alpha)
$$

with $\varepsilon_{u}(T, \alpha) \leq 7.8 * 10^{-3}$ as an upper limit for all cases $(\alpha=0)$.

where:

$$
\begin{aligned}
& \varepsilon_{u}\left(20^{\circ} \mathrm{C}\right)=2.2 * 10^{-3} \\
& \Delta \varepsilon_{u}(T)=(T-20) *\left[4.2 * 10^{-6}+(T-20) * 5.4 * 10^{-9}\right]
\end{aligned}
$$

$f(\alpha)$ is a function of load history. A linear interpolation is applied for intermediate values of load factor $\alpha$ : $f(\alpha)=1(\alpha=0), f(\alpha)=0.227(\alpha=0.1), f(\alpha)=0.066$ $(\alpha=0.2), f(\alpha)=-0.095(\alpha \geq 0.3)$

\subsubsection{Elastic strain}

Elastic strain is:

$$
\varepsilon_{e l}(T, \alpha)=\frac{\sigma(t)}{E(T, \alpha)}
$$

where $\sigma(t)$ is the stress at time $t$ and $E(T, \alpha)$ is Young's modulus as a function of load history and temperature, according to equation (16) to (27). 


\subsubsection{Plastic strain}

Two parts of the stress induced strains at high temperatures, i.e. elastic and plastic strains can be included in a stress-strain relationship according to Fig. 9.

The equation (32) calculates the stress-strain curve:

$$
\sigma(t)=f_{c}(T, \alpha) * \frac{\varepsilon(\sigma(t))}{\varepsilon_{u}(T, \alpha)} * \frac{n}{(n-1)+\left(\frac{\varepsilon(\sigma(t))}{\varepsilon_{u}(T, \alpha)}\right)^{n}}
$$

where $n=3$ for ordinary concrete

The elastic and plastic strains should generally be taken from the measured stress-strain relationship. $\varepsilon_{p l}(T, \alpha)$ is calculated as follows:

$$
\varepsilon_{p l}(T, \alpha)=\varepsilon\left\{\sigma(t), \varepsilon_{u}(T, \alpha), T, \alpha\right\}-\varepsilon_{e l}\{\sigma(t), T, \alpha\}
$$

The plastic strain is also calculated as a shorter notation as follows:

$$
\varepsilon_{p l}(T, \alpha)=\varepsilon\left\{\sigma(t), \varepsilon_{u}(T, \alpha), T\right\}-\varepsilon_{e l}\{\sigma(t), T, \alpha\}
$$

whereby $\varepsilon_{p l} \equiv 0$ if $\varepsilon_{e l}>\varepsilon_{p l}$

where

$\alpha, T=T(t)$ is a parameter for load and temperature and $\varepsilon_{u}=f(T, \alpha)$ is a parameter for load history and temperature.

A numerical approximation for the ascending branch of the stress-strain relationship is:

$$
\varepsilon_{p l}(T, \alpha)=\kappa * \frac{\sigma(t)}{E(T, \alpha)}
$$

The function $\kappa$ given in (Schneider et al. 2008) is as follows:

$$
\kappa=\frac{1}{2} *\left[1-\sqrt{1-\left(\frac{\sigma(t)}{f_{c}(T, \alpha)}\right)^{4}}\right]
$$

\subsubsection{Total mechanical strain}

Thermal induced total strain minus thermal strain is given in the following equation. This equation comprises parts of elastic, plastic and creep strains (Khoury et al. 1985).

$$
\varepsilon_{m}=\varepsilon_{e l}+\varepsilon_{p l}+\varepsilon_{t r}=\varepsilon_{t o t}-\varepsilon_{t h}
$$

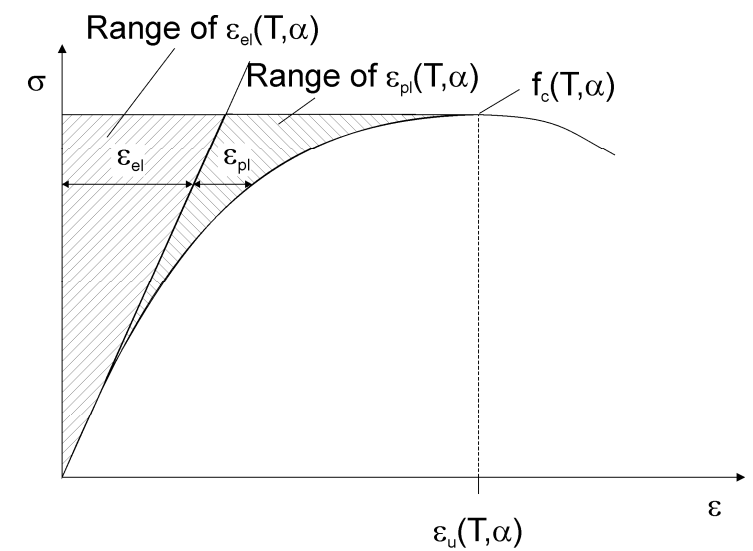

Fig 9 Range of elastic and plastic strain of stress-strain relationship.

$$
\varepsilon_{m}(T)=\frac{\sigma(t)}{E(T)} *(1+\varphi)
$$

The thermal induced strain is relatively independent compared to dependence of Young's modulus by load history (Schneider 1979) and the term $\varepsilon_{t r, c r}=\varphi * \sigma(t) / E(T)$ defined as transient creep in the literature (RILEM TC 129 MHT, 1998). Actually the term comprises elastic, plastic and (pure) transient creep strains as we show below (Schneider et al. 1980). The elastic strain is calculated according to the following equation:

$$
\varepsilon_{e l}(T, \alpha)=\varepsilon_{e l}(T)-\Delta \varepsilon_{e l}(T, \alpha)
$$

The $\varphi$-function is calculated in the next equation. It uses new parameters as shown in Table 1, which were obtained from recent scientific results (Schneider et al. 2008b) based on ongoing research.

$$
\varphi=C_{1} * \tanh \gamma_{w} *(T-20)+C_{2} * \tanh \gamma_{0} *\left(T-T_{g}\right)+C_{3}
$$

The moisture content of concrete is taken into account using equation (41).

$$
\gamma_{w}=0.3 * 10^{-3} * w^{0.5}+2.2 * 10^{-3}
$$

with $\gamma_{w} \leq 2.8 * 10^{-3}$.

where $\mathrm{w}$ is the moisture content of concrete in $\%$ by weight whereby $1 \%<\mathrm{w}<4.5 \%$ (Schneider et al. 2008b).

Table 1 Parameters for transient creep functions of structural concretes (Schneider et al. 2008b).

\begin{tabular}{|c|c|c|c|c|}
\hline Parameter & Dimension & $\begin{array}{c}\text { Quarzit } \\
\text { concrete }\end{array}$ & Limestone concrete & $\begin{array}{c}\text { Lightweight } \\
\text { concrete }\end{array}$ \\
\hline $\mathrm{C}_{1}$ & 1 & 2.50 & 2.50 & 2.50 \\
\hline $\mathrm{C}_{2}$ & 1 & 0.70 & 1.40 & 3.00 \\
\hline $\mathrm{C}_{3}$ & 1 & 0.70 & 1.40 & 2.90 \\
\hline$\gamma_{0}$ & ${ }^{\circ} \mathrm{C}^{-1}$ & $7.5^{*} 10^{-3}$ & $7.5^{*} 10^{-3}$ & $7.5^{*} 10^{-3}$ \\
\hline $\mathrm{T}_{\mathrm{g}}$ & ${ }^{\circ} \mathrm{C}$ & 800 & 700 & 600 \\
\hline
\end{tabular}




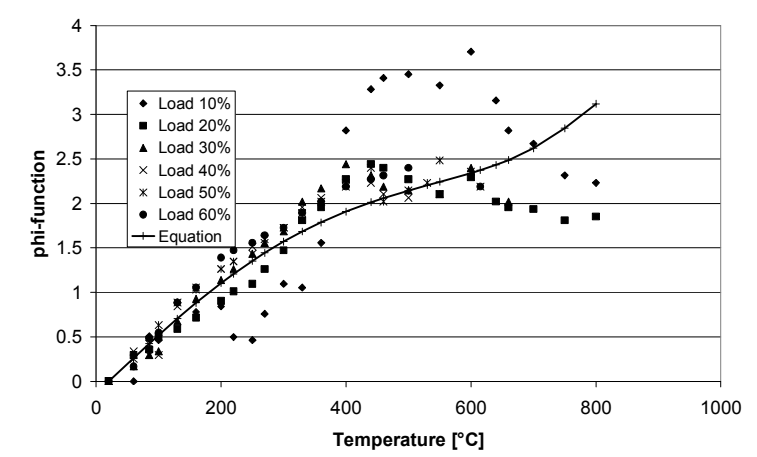

Fig. 10 Transient creep function for siliceous concrete. (Schneider et al. 2008b).

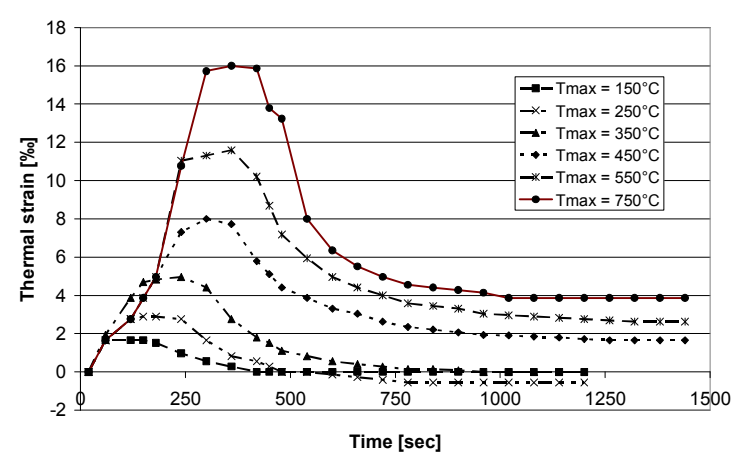

Fig. 11 Thermal strain after heating and cooling. (Schneider et al. 1977).

Figure 10 shows the $\varphi$-function for siliceous concrete. The equation (41) above is similar to the equation for creep strain at room temperature. That is why the $\varphi$ function is called "transient creep function" in RILEM literature (Schneider 1979), although it was known that $\varphi$ contains in addition small parts of plastic and elastic strains (Schneider 1979).

Therefore it was also called "thermal induced strain" according to (Khoury et al. 1985b). The pure transient creep will not be calculated numerically within the proposed calculation procedure described below but the exact relationship is given in equation (42) and extended to the final relationship equation (55).

After calculation of plastic strains and elastic strains the pure transient creep strain $\varepsilon_{t r}(T, \alpha)$ should be calculated as follows:

$$
\varepsilon_{t r}(T, \alpha)=\varepsilon_{m}(T)-\varepsilon_{e l}(T, \alpha)-\varepsilon_{p l}(T, \alpha)
$$

\subsection{Development of different strains in com- pression at high temperatures in a concrete model due to transient effects}

\subsubsection{Thermal strain during heating and cooling}

The thermal strain increases in any case by heating up to $650^{\circ} \mathrm{C}$. Above that point thermal strain gradual slightly decreases in a gradual fashion until the final strain is $14.8 \%$ at a temperature of $1000^{\circ} \mathrm{C}$. At each time step there is a final strain according to the reached temperature $T_{\max }$. It is essential to define the maximum thermal strain during heating:

$$
\varepsilon_{t h}{ }^{n}=\varepsilon_{t h}\left(T_{\max }\right)
$$

where superscript $\mathrm{n}$ stands for each time step.

During cooling down the thermal strain is irreversible, as shown in Fig. 11. That is because during heating up to the maximum temperature generally a two dimensional crack system develops. These cracks do not close completely during cooling down, which leads to residual deformations (Schneider et al. 1977).

\subsubsection{Elastic and plastic strain during heating up including load history}

Any time in the ascending branch the elastic strain is:

$$
\varepsilon_{e l}{ }^{n}=\varepsilon_{e l}(T, \alpha)
$$

During cooling down, the elastic strain is reversible. The deformation energy may be released after heating up assuming that further cracking takes places during cooling, which is not always the case.

Plastic strain cannot decrease because it is irreversible. Subsequent behaviour in the ascending and descending branches of the stress-strain relationship is assumed. The plastic strains are calculated as described before including the load history in the stress-strain relation. If temperature or load history decreases the plastic strain, then the deformation is taken as permanent.

$$
\varepsilon_{p l}{ }^{n}=\varepsilon_{p l}\left(T_{\max }, \alpha\right)
$$

During cooling down the deformations are constant. In the range of $\varepsilon_{p l}+\varepsilon_{e l} \geq \varepsilon_{u}$. The deformation may be calculated according to the linear model of EC2 (Eurocode 2, Part 1-2, 2004) given in Table 2. where:

$\varepsilon_{u}(T, \alpha)=$ ultimate strain in ascending branch

$\varepsilon_{u, 1}(T, \alpha)=$ maximum strain of the descending branch of stress-strain-relation-ship, according to (Eurocode 2, Part 1-2, 2004)

\subsubsection{Transient creep during heating up and load history}

The component of deformation of the creep-function is

Table 2 Ultimate strain and stress induced strain in ascending and descending branch of the stress-strain relationship (Eurocode 2, Part 1-2, 2004).

\begin{tabular}{|c|c|}
\hline $\begin{array}{c}\text { Concrete } \\
\text { Temperature }\end{array}$ & $20 \ldots 1100{ }^{\circ} \mathrm{C}$ \\
\hline $\begin{array}{c}\varepsilon_{u}(T, \alpha) \text { see } \\
\text { chapter } 2.3 .4\end{array}$ & $\varepsilon_{u}(T, \alpha)=\varepsilon_{u}\left(20^{\circ} \mathrm{C}\right)+\Delta \varepsilon_{u}(T) * f(\alpha)$ \\
and \\
$\varepsilon_{u}(T, \alpha) \leq 7.8 * 10^{-3}$
\end{tabular}


irreversible. The consideration is discrete. For each time step, there exists a point of the creep function that belongs to the thermal induced strain and a part of transient creep strain that depends on load history and temperature (Bockhold and Stangenberger 2004).

By increasing the temperature and changing the load simultaneously, the parts of plastic and transient creep parts are irreversible. The part of elastic strain $\Delta \varepsilon_{e l}$ is reversible. The stepwise calculation of strains based on the total strain approach is done as follows:

$$
\varepsilon_{t r}{ }^{n}=\varepsilon_{t r}{ }^{n-1}+\Delta \varepsilon_{t r}(T, \alpha)
$$

where $\mathrm{n}$ indicates the new time step with $T=T(n)$ and $\mathrm{n}$-1 the old time step with

$\varepsilon_{t r}{ }^{n} \geq \varepsilon_{t r}{ }^{n-1}$ (temperature increases and stress $=$ constant or increase)

$$
\Delta \varepsilon_{t r}(T, \alpha)=\varepsilon_{t r}{ }^{n}-\varepsilon_{t r}{ }^{n-1}
$$

with $\varepsilon_{t r}{ }^{n}<\varepsilon_{t r}{ }^{n-1}$ (temperature increases and stress decreases)

$$
\Delta \varepsilon_{t r}(T, \alpha)=\max \varepsilon_{t r}{ }^{n}-\Delta \varepsilon_{e l}{ }^{n}(T, \alpha)
$$

Whereas $\Delta \varepsilon_{e l}$ is:

$$
\Delta \varepsilon_{e l}(T, \alpha)=\varepsilon_{e l}(T, \alpha)-\varepsilon_{e l}(T)
$$

From the basic equations, we obtain:

$$
\begin{aligned}
& \varepsilon_{m}(T)=\varepsilon_{e l}(T, \alpha)+\varepsilon_{p l}(T, \alpha)+\varepsilon_{t r}(T, \alpha) \\
& \varepsilon_{m}(T)=\frac{\sigma(t)}{E(T)} *(1+\varphi) \\
& \varepsilon_{e l}(T)=\frac{\sigma(t)}{E(T)} \\
& \frac{\varphi * \sigma(t)}{E(T)}=\varepsilon_{p l}(T, \alpha)+\Delta \varepsilon_{e l}(T, \alpha)+\varepsilon_{t r}(T, \alpha)
\end{aligned}
$$

For the pure transient creep we obtain from equation (42) finally:

$$
\varepsilon_{t r}(T, \alpha)=\frac{\varphi * \sigma(t)}{E(T)}-\varepsilon_{p l}(T, \alpha)-\Delta \varepsilon_{e l}(T, \alpha)
$$

It is astonishing to observe that the influence of load history originates from plasticity effects and to a small extent from the load effect on the modulus of elasticity. The pure transient function according to equation (55) is obviously of high complexity and up to now not quantitatively determined for OPC. The possible data for such a determination are given in the equation cited above.

\subsection{Model in tension}

The concrete model for tensile stress is assumed as one tenth of the stress-strain curve for compression, including no load history and no creep (Eurocode 2, Part 1-1,

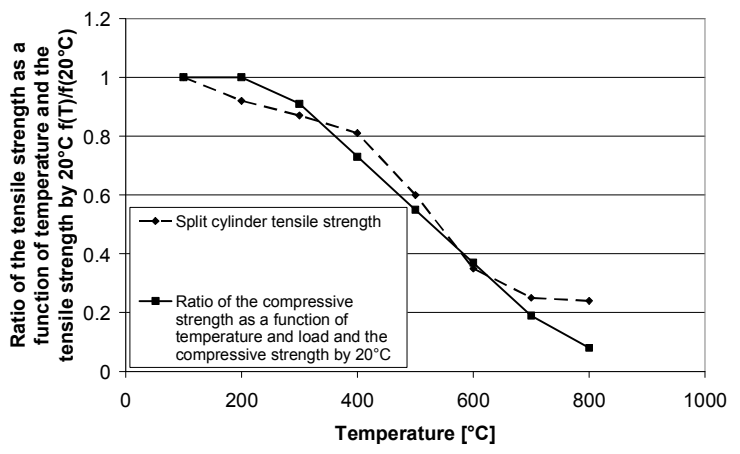

Fig. 12 Ratio of split cylinder tensile strength and compressive strength at high temperatures. (Schneider 1982).

2004). Figure 12 indicates a nearer identical behaviour at high temperatures between compression and tensile strength according to split cylinder tensile strength results.

Tensile strength at high temperatures $f_{T}(T, \alpha=0)$ is calculated as one tenth of the data according to equations (6) to (9).

Compared with the concrete model in compression, the plastic deformation in tension could decrease, because of the relocation of loads into compression; open cracks could close again and change the prefix of stress. The concrete model in tensile is:

$$
\varepsilon_{t o t, t}=\varepsilon_{e l, t}+\varepsilon_{p l, t}+\varepsilon_{t h}
$$

where subscript $\mathrm{t}$ stands for tension.

\subsection{Failure model}

To calculate the specimens in a concrete model with finite element analysis we need a model to find the failure point. That is why the following assumption was used in the calculation.

The failure of concrete starts due to crack opening in compression due to mechanical stress, if $\frac{\sigma(t)}{f_{c}(T)}>0$. On the other hand the failure of concrete may occur due to pure tensile stresses. In reality the whole stresses are transferred to the reinforcement steel and the specimens will not fail due to tensile failure of concrete. Without reinforcement the whole concrete structure fails under tension in this case. As long as we consider concrete as basic material the cracking is a dominant factor.

Cracks start directly due to the release of tensile strain and plastic deformation energy exceeding the surface crack energy. The failure may be estimated by the following criteria (Diederichs et al. 1987):

- Temperature: $T_{\max } \geq T_{\text {critical }}(\alpha)$

- Deformation rate: $v\left(\dot{\varepsilon}_{\text {tot }}\right) \geq v\left(\dot{\varepsilon}_{\text {critical }}\right)$

- Maximum deformation: $\dot{\varepsilon}_{\text {tot }} \geq \dot{\varepsilon}_{\text {critical }}$

In the case of high temperatures, concrete under dif- 
ferent constant load fails during heating up, as shown in Fig. 13.

Note that the maximum of critical concrete temperature is in the range of 850 to $950^{\circ} \mathrm{C}$ for loaded structures. The upper level of fatigue load at this temperature range is $\alpha=0.1$. That means, if you heat up the concrete specimen continuously with a load factor of $\alpha=0.1$ the specimen fails at about $900^{\circ} \mathrm{C}$.

From the test results for the total deformation strains $\dot{\varepsilon}_{t o t}$ one may conclude that the deformation rate $v\left(\dot{\varepsilon}_{t o t}\right)$ plays a dominant role during the simulation of transient load history. If the maximum deformation rate is exceeded, the concrete fails. That means in this case the ratio $\frac{\sigma(t)}{E(T, \alpha)}$ during heating can not be larger than the results of the deformation ratio per second. The deformation rate is shown in Fig. 14. The limit of the failure curve presents the failure of concrete, if the deformation rate is larger than the limit curve based on the range of failure according to (Schneider 1979). The observed failure rates $v\left(\dot{\varepsilon}_{\text {tot }}\right)$ range from $5 * 10^{-4} \%$ o/s to $35 * 10^{-4} \% \mathrm{o} / \mathrm{s}$ depending on the load level and the test temperature. The failure rates are based on the crack development in concrete.

Cracks develop in physical-chemical conversion by thermal destruction of CSH phases in cement mortar and of crystal conversion of aggregates respectively. These phenomena are considered to decrease the compressive strength and the critical temperature. Furthermore cracks are influenced by the kinetic parameters, such as activation energy, reaction rate of dehydration products and reaction rate of concrete aggregates which leads to the time and temperature dependent loss of strength (Schneider 1974). Drying of concrete at high temperatures is also responsible for cracks (Cruz and Lorenzo 2007). In the model the shrinkage strain during heating is included in the transient thermal strain part which depends on the type of concrete (Hirashima et al. 2007). The ultimate strain of ordinary concrete is considered as a function of load factor $\alpha$ and temperature in section 2.3.4. It was observed that relating the ultimate strain of loaded specimens at high temperatures just to the ultimate strain at $20^{\circ} \mathrm{C}$ is not sufficient. A part of the larger deformation properties is compensated by the transient creep. The ability of concrete for plasticizing at high loads is depleted, that is why the ultimate strain is unexpectedly low (Schneider 1988), whereas the total strains under failure conditions are very high.

\subsection{Cooling down}

Thermal strain of ordinary concrete is normally irreversible. Figure 15 shows the residual strains of concretes after heating up to different temperatures and immediate cooling thereafter. This behaviour could be estimated as irreversible like plastic deformations.

The behaviour of concrete in the phase of cooling down also depends on load history. Figure 16 shows the

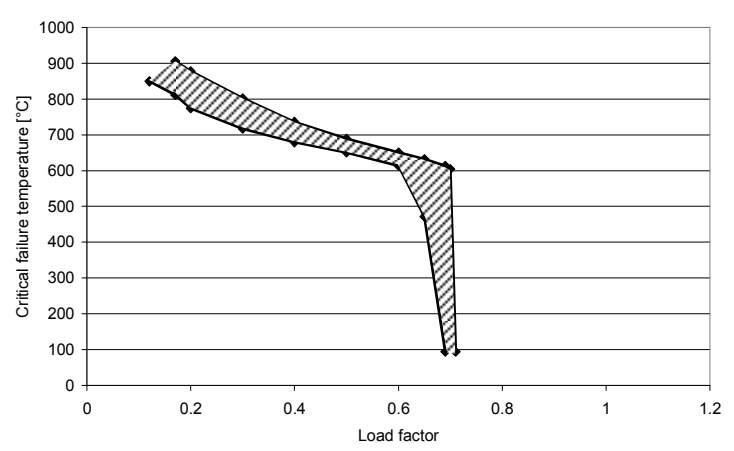

Fig. 13 Critical concrete temperatures of siliceous concrete with constant load during heating up. (Schneider 1979b).

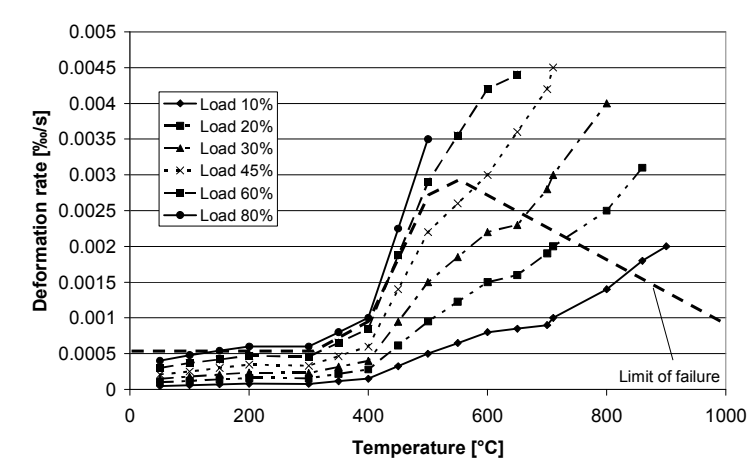

Fig. 14 Deformation rate under different load factors during heating up. (Schneider 1979).

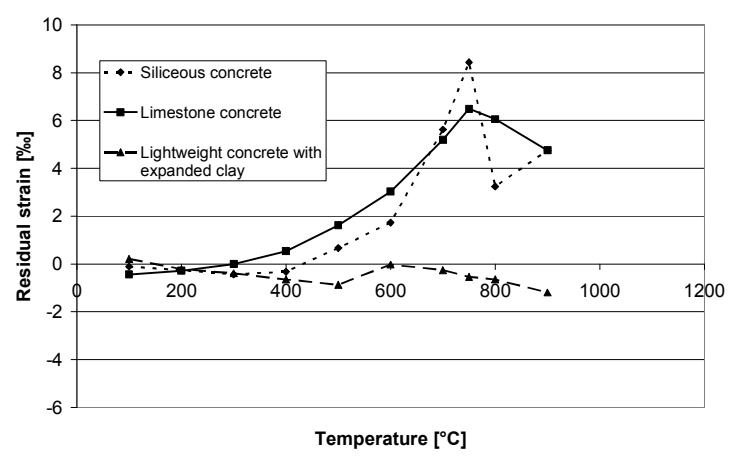

Fig. 15 Residual strains after heating up to a certain temperature $T_{\max }$ and cooling down to $20^{\circ} \mathrm{C}$ of different types of concretes. (Schneider 1979).

total strain for siliceous concrete.

Data were obtained for the heating/cooling rates between 0.5 to $10 \mathrm{~K} / \mathrm{min}$ (Anderberg and Thelanderson 1976). The residual strain according to lines in Fig. 16 in the temperature range between $600^{\circ} \mathrm{C}$ to $20{ }^{\circ} \mathrm{C}$, as follows:

For $\alpha=0$ the total strain is identical thermal strain $\varepsilon_{t h}$ :

$\varepsilon_{\text {th }}{ }^{\text {cool }}(T)=\varepsilon_{\text {tot }}\left(T_{\max }\right)-\Delta \varepsilon_{0}$

whereby: 


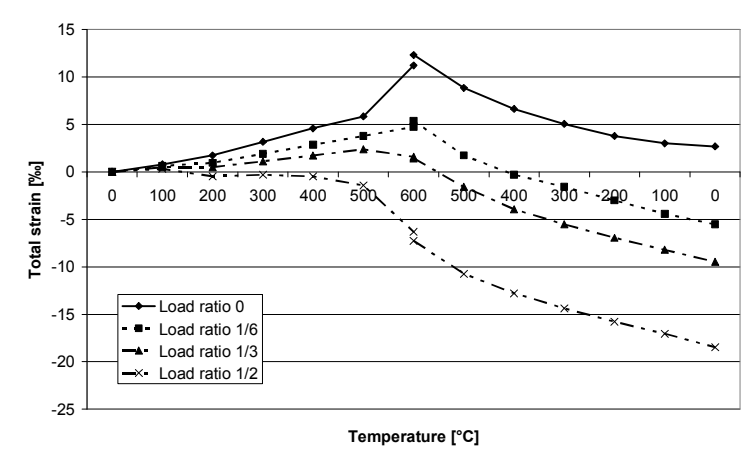

Fig. 16 Total deformation of siliceous concrete under constant load during a complete heating-cooling-cycle. (Anderberg and Thelanderson 1973).

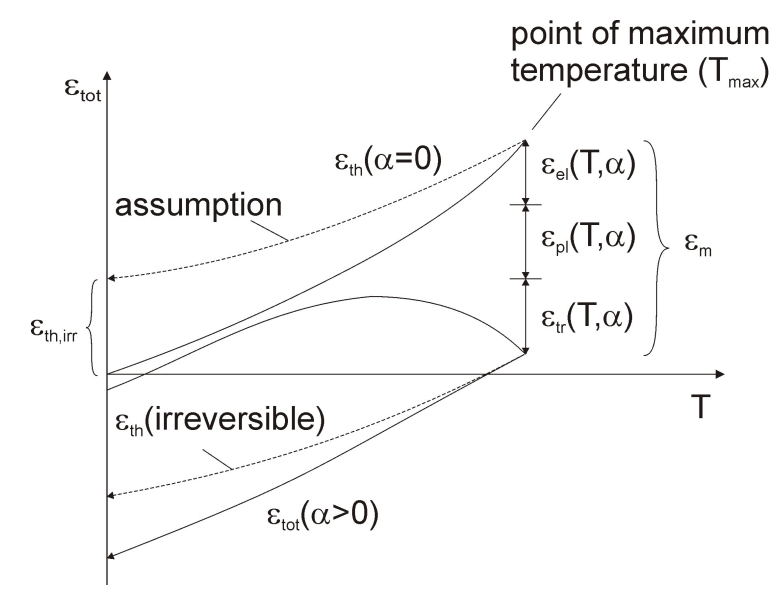

Fig. 17 Residual strains of loaded specimens during heating and cooling down.

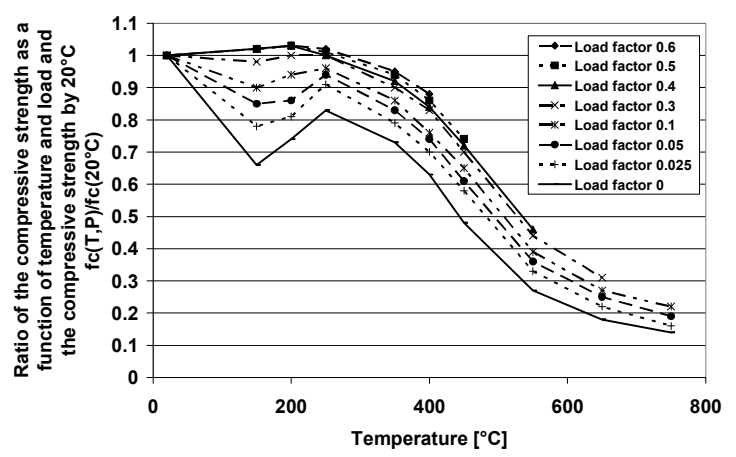

Fig. 18 Residual strength of siliceous concrete under different sustained loads during heating up. (Schneider and Horvath 2003).

$$
\Delta \varepsilon_{0}=1.445 * 10^{-3} e^{3.4 * 10^{-3} * T_{\max }}-1.445 * 10^{-3} * e^{3.4 * 10^{-3} * T(n)}
$$

with $T(n)$ as temperature at each time step $\mathrm{n}$.

This behaviour is indicated due to residual crack opening because cracks do not close completely during cooling down.

The following equations are also affected by cracks during heating up to a maximum temperature in the range $600^{\circ} \mathrm{C} \leq \mathrm{T}_{\max } \leq 20^{\circ} \mathrm{C}$, which is why it presents an empirical behaviour of concrete during cooling down.

For $\alpha>0$ the total strain is:

$$
\varepsilon_{\text {tot }}{ }^{\text {cool }}(T, \alpha)=\varepsilon_{\text {tot }}\left(T_{\max }, \alpha\right)-\Delta \varepsilon_{\alpha}
$$

whereby:

$$
\begin{aligned}
\Delta \varepsilon_{\alpha}(T, \alpha)= & {\left[1.9 * 10^{-8} * T_{\max }{ }^{2}+8 * 10^{-6} * T_{\max }+3.2 * 10^{-4}\right] } \\
& -\left[1.9 * 10^{-8} * T^{2}+8 * 10^{-6} * T+3.2 * 10^{-4}\right]
\end{aligned}
$$

In numerous research projects we observed that the above-mentioned equations are available for maximum temperature from $150^{\circ} \mathrm{C}$ to $750^{\circ} \mathrm{C}$ (Schneider et al. 1977, Schneider 1979) and (Diederichs et al. 1987).

Residual strains of loaded specimens were predicted from the sum of residual strains of the unloaded specimens, load induced thermal strain, constant temperature creep and any expansion during cooling down (Khoury et al. 1986). The principal sketch in Fig. 17 shows this effect.

After the unstressed first deformation $(\alpha=0)$ an irreversible decreasing of thermal strain is observed. In loaded concrete the same irreversible part of thermal strain occurs and an added part of transient strain. For each maximum temperature, there is a cooling function that depends on load history. This is taken into account according to the equations (59) and (60).

\subsection{Residual properties}

During a temperature cycling many different failure mechanisms may arise. They are governed by the load bearing strength and the residual strength after cooling down. Thermal damages that might occur are:

- Chemical dehydratation reactions of cement mortar and aggregates

- Physical conversions

- Cracks, increasing of pores content

The low residual strength after cooling down of concrete at high temperatures is shown in Fig. 18.

It is also determined as a function of load history. The relative decrease of compressive strength around $150^{\circ} \mathrm{C}$ by lower load factors depends on the loss of moisture in the structure and is not due to a thermal reaction inside of the concrete.

Young's modulus and the residual strain after different thermal cycles must be determined experimentally before the residual load bearing capacity of members can be calculated.

The residual strain can be approximately calculated according to section 2.8. Concerning the reduction of Young's modulus at elevated temperature the results from Fig. 19 may be used. The Fig. 19 shows the ratio of Young's modulus after heating up to a maximum temperature $T_{\max }$ and testing after cooling down to $20^{\circ} \mathrm{C}$ $\mathrm{E}_{\text {residual }}\left(T_{\max }\right)$ divided by Young's modulus at $20^{\circ} \mathrm{C}$ $\mathrm{E}\left(20^{\circ} \mathrm{C}\right)$.

It seems that the relation between Young's modulus at 


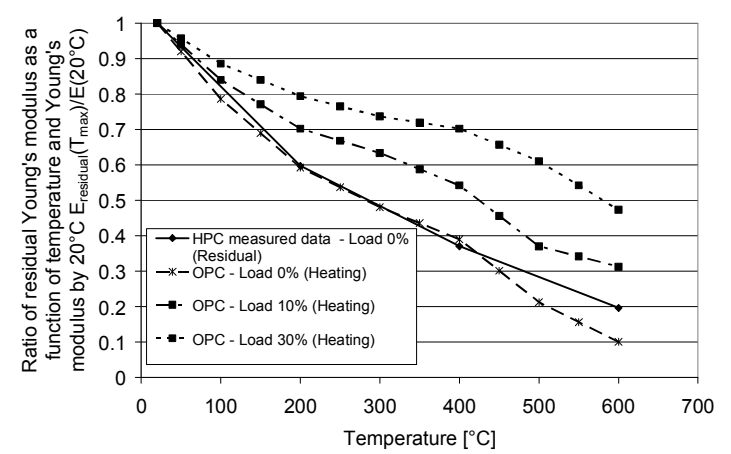

Fig. 19 Reduction of Young's modulus at elevated temperature (Residual test) of high strength concrete. (Watanabe and Horiguchi 2008).

elevated temperatures and the Young's Modulus at $20^{\circ} \mathrm{C}$ is similar for ordinary concrete and high-performance concrete (Schneider et al. 1977, Watanabe and Horiguchi 2008). The residual Young's modulus is greater or equal to the minimum value of Young's modulus during heating, which must be considered according to Fig. 19.

\section{Conclusion}

To calculate the load bearing behaviour of structures subjected to fire the material laws for the most important material properties of ordinary concrete were developed. This model was made to complete the existing concrete model of EC2 to consider thermal creep and the effect of load history. It is possible with this model to consider the load history in all phases of thermal exposure. With this complex model, one can calculate total strain with variances of load history and temperatures. Different parts of deformations are approximated with discrete equations interacting in a new concrete model. This technique is usable to calculate realistically the behaviour of structures (Franssen 2004, Li and Purkiss 2005, Anderberg 2008), especially in the case of restraint and during cooling, which is not possible in EC2.

By considering the load history during heating up in several cases an increasing load bearing capacity due to a higher stiffness of concrete may be obtained. With this model it is possible to consider the thermal-physical behaviour of material laws for the calculation of reinforced concrete structures. Application of this model to the ordinary calculation system of EC2 will lead to a better evaluation of the safety level. This opens the way to optimizing reinforced concrete structures and material design.

\section{References}

Anderberg, Y. and Thelanderson, S. (1973). "Stress and deformation characteristics of concrete at high temperatures, 1. General discussion and critical review of literature." Bulletin 34 Lund: Division of
Structural Mechanics and Concrete Constructions, Institute of Technology Lund.

Anderberg, Y. and Thelanderson, S. (1976). "Stress and deformation characteristics of concrete at high temperatures, 2. Experimental investigation and material behaviour model." Bulletin 54 Lund: Division of Structural Mechanics and Concrete Constructions, Institute of Technology Lund.

Anderberg, Y. (2008). "The impact of various material models on structural fire behaviour prediction." In: K. H. Tan, V. K. R. Kodur and T. H. Tan, Eds. Fifth International Conference - Structures in Fire SIF 08, Singapore 28-30 May 2008. Singapore: Research Publishing Service, 253-265.

Bockhold, J. and Stangenberg, F. (2004). "Modellierung des nichtlinearen Kriechens von Beton. "Beton- und Stahlbetonbau, 99(3), 209-216.

Cruz, A. and Lorenzo, F.-M. (2007). "Dehydratation and rehydratation processes in cementious materials after fire - Correlation between micro and macrostructural transformations.” In: J. P. C. Rodrigues, G. A. Khoury and N. P. Hoj, Eds. International Workshop - Fire Design of Concrete Structures: From Materials Modelling to Structural Performance, Coimbra 8-9 November 2007. Coimbra: Department of Civil Engineering, Universidade de Coimbra, 69-78.

Diederichs, U., Ehm, C., Hinrichsmeyer, K., Schneider, U. and Wydra, W. (1987). "Hochtemperaturverhalten von Festbeton." Braunschweig: Sonderforschungsbereich 148 - Brandverhalten von Bauteilen - TU Braunschweig.

Eurocode 2: "Design of concrete structures Part 1-1: General rules and rules for buildings." (2004a).

Eurocode 2: "Design of concrete structures - Part 1-2: General rules - Structural fire design.” (2004b).

Franssen, J.-M. (2004). "Plastic analysis of concrete structures subjected to fire." In: P. G. Gambarova, R. Falicetti, A. Meda and P. Riva, Eds. International Workshop - Fire Design of Concrete Structures: What now? What next?, Milano 2-3 December 2004. Brescia: Starrylink Editrice Brescia, 133-145.

Hirashima, T., Toyoda, K., Yamashita, H., Tokoyoda, M. and Uesugi, H. (2007). "Compression tests of highstrength concrete cylinder at elevated temperature." In: J. P. C. Rodrigues, G. A. Khoury and N. P. Hoj, Eds. International Workshop - Fire Design of Concrete Structures: From Materials Modelling to Structural Performance, Coimbra 8-9 November 2007. Coimbra: Department of Civil Engineering, Universidade de Coimbra, 47-58.

Khoury, G. A., Grainger, B. N. and Sullivan, P. J. E. (1985a). "Transient thermal strain of concrete: Literature review, conditions with specimens and behaviour of individual constituents." Magazine of Concrete Research, 37(132), 131-144

Khoury, G. A., Grainger, B. N. and Sullivan, P. J. E. (1985b). "Strain of concrete during first heating to $600^{\circ} \mathrm{C}$ under load." Magazine of Concrete Research, 
37(133), 195-215.

Khoury, G. A., Grainger, B. N. and Sullivan, P. J. E. (1986). "Strain of concrete during first cooling from $600^{\circ} \mathrm{C}$ under load." Magazine of Concrete Research, 38(134), 3-12.

Li, L. and Purkiss, J. (2005). "Stress-strain constitutive equations of concrete material at elevated temperatures." Fire Safety Journal, 40(7), 669-686.

Li, Y., Wu, B. and Schneider, M. (2009). "Numerical modelling of restrained RC columns in fire." In: Y. Yuan, J. Cui and H.A. Mang, Eds. International Symposium on Computational Structural Engineering, Shanghai 22-24 June 2009, Heidelberg: Springer Science+Bussiness Media B.V., 951-958.

RILEM TC 129-MHT (1998). "Test methods for mechanical properties of concrete at high temperatures - Recommendation: Part 7: Transient creep for service and accident conditions." Materials \& Structures, 31, 290-295.

RILEM TC 200-HTC (2007). "Mechanical concrete properties at high temperature - Recommendation Part 1: Modelling and applications." Materials \& Structures, 40, 841-853.

Schneider, U. (1974). "Zur Kinetik Festigkeitsmindernder Reaktionen in Normalbeton bei hohen Temperaturen." Braunschweig: Schriftenreihe des Sonderforschungsbereichs 148, Heft 3 - TU Braunschweig.

Schneider, U., Diederichs, U. and Weiß, R. (1977). "Hochtemperaturverhalten von Festbeton." Braunschweig: Sonderforschungsbereich 148 Brandverhalten von Bauteilen - TU Braunschweig.

Schneider, U., Diederichs, U., Rosenberger, W. U. and Weiß, R. (1980). "Hochtemperaturverhalten von Festbeton." Braunschweig: Sonderforschungsbereich 148 - Brandverhalten von Bauteilen - TU Braunschweig.

Schneider, U. (1979a). "Ein Beitrag zur Frage des Kriechens und der Relaxation von Beton unter hohen Temperaturen." Braunschweig: Heft 42 - Institut für Baustoffe, Massivbau und Brandschutz, TU Braunschweig.

Schneider, U. (1979b). "Ein Beitrag zur Klärung des Kriechens und der Relaxation von Beton unter instationärer Temperaturentwicklung." Berlin: Forschungsbeiträge für die Baupraxis, Verlag Ernst \& Sohn.

Schneider, U. (1982). "Behaviour of concrete at high temperatures.” Berlin: Verlag Ernst \& Sohn.

Schneider, U. (1988). "Concrete at high temperatures A reneral review." Fire Safety Journal, 13(88), 55-68.

Schneider, U. and Horvath, J. (2003). "Behaviour of ordinary concrete at high temperatures." Wien: Heft 9 - Institut für Baustofflehre, Bauphysik und Brandschutz, TU Wien.

Schneider, U., Schneider, M. and Franssen, J.-M. (2008a). "Consideration of nonlinear creep strain of siliceous concrete on calculation of mechanical strain under transient temperatures as a function of load history." In: K.H. Tan, V.K.R. Kodur and T.H. Tan, Eds. Fifth International Conference - Structures in Fire SIF 08, Singapore 28-30 May 2008. Singapore: Research Publishing Service, 463-476.

Schneider, U., Lebeda, C. and Franssen, J.-M. (2008b). "Baulicher Brandschutz." Berlin: Bauwerk Verlag $\mathrm{GmbH}$.

Schneider, U., Schneider, M. and Franssen, J.-M. (2009a). "Numerical evaluation of load induced thermal strain in restraint structures compared with an experimental study on reinforced concrete columns." In: Interscience Communications, Eds. 11th International Conference and Exhibition, Fire and Materials, San Francisco26-28 January 2009, 26th 28th January 2009, London: Interscience Communications Ltd, 485-497.

Schneider, U., Schneider, M. and Franssen, J.-M. (2009b). "Numerical evaluation of load induced thermal strain in restraint structures - Calculation of a tunnel cross section subjected to fire.” In: F. Wald, P. Kallerova and J. Chlouba, Eds. International Conference Applications of Structural Fire Engineering, Prague 19-20 February 2009, Prague: Prazska technika, Czech University of Technology, 289-294.

Shi, X., Tan, T-H., Tan, K-H. and Guo, Z. (2002). "Concrete constructive relationships under different stress-temperature-paths." Journal of Structural Engineering, 12(02), 1511-1518.

Watanabe, K. and Horiguchi, T. (2008). "Effect of elevated temperatures on flexural behaviour of hybrid reinforced high strength concrete." In: K. H. Tan, V. K. R. Kodur and T. H. Tan, Eds. Fifth International Conference - Structures in Fire SIF 08, Singapore 2830 May 2008. Singapore: Research Publishing Service, 430-439. 